\title{
The impact of a week of simulated night work on sleep, circadian phase, and performance
}

\author{
N Lamond, J Dorrian, G D Roach, K McCulloch, A L Holmes, H J Burgess, A Fletcher, D Dawson
}

Occup Environ Med 2003;60:e13 (http://www.occenvmed.com/cgi/content/full/60/11/el3)

See end of article for authors' affiliations

\section{Correspondence to:} Dr N Lamond, The Centre for Sleep Research, 5th Floor, Basil Hetzel Institute, The Queen Elizabeth Hospital, Woodville Rd Woodville SA 5011 .

Australia; nicole.lamond@ unisa.edu.au

Accepted

14 February 2003

\begin{abstract}
Aims: To investigate factors that may contribute to performance adaptation during permanent night work. Methods: Fifteen healthy subjects participated in an adaptation and baseline night sleep, directly followed by seven simulated eight-hour night shifts (2300 to 0700 hours). At the end of each shift they were taken outside and exposed to natural light for 20 minutes. They then slept from approximately 0800 hours until they naturally awoke.

Results: There was a significant increase in mean performance on a visual psychomotor vigilance task across the week. Daytime sleep quality and quantity were not negatively affected. Total sleep time (TST) for each of the daytime sleeps was reduced, resulting in an average cumulative sleep debt of 3.53 hours prior to the final night shift. TST for each of the daytime sleep periods did not significantly differ from the baseline night, nor did TST significantly vary across the week. There was a significant decrease in wake time after sleep onset and sleep onset latency across the week; sleep efficiency showed a trend towards greater efficiency across the consecutive daytime sleeps. Hours of wakefulness prior to each simulated night shift significantly varied across the week. The melatonin profile significantly shifted across the week. Conclusions: Results suggest that under optimal conditions, the sleep debt that accumulates during consecutive night shifts is relatively small and does not exacerbate decrements in night-time performance resulting from other factors. When sleep loss is minimised, adaptation of performance during consecutive night shifts can occur in conjunction with circadian adaptation.
\end{abstract}

$\mathrm{t}$ is now well established that night work negatively impacts on alertness and performance. ${ }^{1-3}$ These performance decrements are primarily a result of the conflict between night work schedules and circadian rhythms. Specifically, night work is problematic because shift workers are working when the underlying circadian rhythm of performance is lowest. ${ }^{4-6}$ Further problems arise because shiftworkers are attempting to sleep during the day when the body is usually active. ${ }^{7-10}$ As a result, day sleep following a night awake is typically shorter and of poorer quality than night sleep, even under optimal conditions. ${ }^{11} 12$ Due to frequent sleep disruption, cumulative sleep loss is a salient problem among shiftworkers working a series of night shifts. ${ }^{13}$

It is possible then, that many of the adverse consequences of shiftwork may be reduced or eliminated if a phase shift of circadian rhythms occurs, such that they are better aligned with the new sleep-wake schedule. That is, night workers should experience greater alertness while at work and daytime sleep of longer duration and better quality. More specifically, performance decrements should decrease in conjunction with circadian adaptation. ${ }^{14}$ However, evidence suggests that the timing of the internal circadian rhythms adjust very slowly to changes in the sleep/wake cycle ${ }^{15-17}$ and usually require several days to several weeks of consecutive night shifts to re-entrain. ${ }^{18}{ }^{19}$ Even then, circadian adaptation is usually only partial, ${ }^{14} 2021$ or in extreme cases, not at all. ${ }^{22}$ Furthermore, as shiftworkers often choose to return to night sleep and daytime activities on their days off, their altered sleep-wake schedule is not maintained long enough to allow sufficient adaptation.

In a recent study by our laboratory investigating the effects of a week of simulated night work on neurobehavioural performance, significant deficits were noted. ${ }^{23}$ One of the most interesting findings in this study, however, was that performance substantially improved over the week. This sharply contrasts with previous studies of shiftworkers. For example, Tilley and colleagues ${ }^{12}$ showed continued deterioration in performance over the course of five consecutive nights. In this study, it was apparent that the primary circadian performance deficit was exacerbated by a secondary loss of sleep effect. Specifically, the authors observed a 1.52 hours reduction in each of the daytime sleep periods, resulting in a cumulative sleep debt equivalent to one night of sleep by the end of the week. As no measure of circadian phase was included in the study, the degree of circadian adaptation, if any, was not assessed. It is therefore impossible to determine whether sleep loss was the sole factor influencing night-time performance.

The aim of this study was to investigate factors that may contribute to performance adaptation during permanent night work. To do this, the impact of a week of simulated night work on (1) night-time performance, (2) daytime sleep quality and quantity, (3) cumulative sleep debt, (4) circadian phase, and (5) prior wakefulness, was examined.

\section{METHODS}

\section{Subjects}

Fifteen healthy individuals (eight females, seven males) aged 18-27 years, with an average body mass index (22.3 (2.3) $\left.\mathrm{kg} / \mathrm{m}^{2}\right)$, participated in the current study. Subjects were nonsmokers who did not regularly consume large amounts of caffeine ( $<350 \mathrm{mg} /$ day) or alcohol ( $\leqslant 6$ drinks/week), and

\footnotetext{
Abbreviations: ANOVA, analysis of variance; DLMO, dim light melatonin onset; EEG, electroencephalogram; NREM, non-rapid eye movement sleep; PSG, polysomnographic; PVT, psychomotor vigilance task; REM, rapid eye movement sleep; RT, response time; SOL, sleep onset latency; SPT, sleep period time; SSS, Stanford Sleepiness Scale; SWS, slow wave sleep; TST, total sleep time; WASO, wake time after sleep onset
} 
Main messages

- The findings support the notion that competing social factors are a primary reason for the reduced daytime sleep quality and quantity of shiftworkers.

- In the absence of social factors and environmental disturbances, the sleep debt that accumulates during consecutive night shifts is relatively small and thus does not exacerbate decrements in night-time performance resulting from other factors.

- Adaptation of performance during consecutive night shifts can occur when sleep loss is minimised and circadian adaptation maximised.

participated in a moderate amount of exercise $(\leqslant 10 \mathrm{~h} / \mathrm{wk})$. Those recruited had no current health problems and were not taking any medication other than an oral contraceptive (all females). Subjects reported no history of sleep problems and were not habitual nappers, nor had they undertaken shift work or transmeridian travel in the past month. Before the study commenced, subjects were required to give written informed consent, and the protocol was approved by the Queen Elizabeth Hospital and the University of South Australia Human Research Ethics Committee using guidelines established by the National Health and Medical Research Council of Australia.

\section{Procedure}

Figure 1 presents a schematic representation of the protocol. Participants were required to attend the laboratory for nine consecutive nights: an adaptation and a baseline night sleep, directly followed by seven simulated night shifts and the subsequent daytime sleep periods. On both the adaptation and baseline night, subjects arrived at the laboratory at 1700 hours, and were assigned to their individual bedroom. Using prestudy sleep diary and wrist actigraph data (not reported here), average bedtimes for the previous week were determined and then assigned as that subject's bedtime for these adaptation and baseline nights. Subjects were instructed to sleep until they naturally woke. After they awoke, subjects were free to leave the laboratory and follow their normal daily routines until they returned to the laboratory at 1700 hours.

Following the baseline night, subjects began the seven nights of simulated shiftwork. They were instructed to arrive at the laboratory by 1900 hours each night, or at 1800 hours if they required dinner. From 2000 hours onwards, participants were confined to the living quarters where they were allowed to read, watch TV, study, listen to music, or play games. Saliva samples were collected at half hourly intervals from 2000 hours to bedtime, and subsequently assayed for the hormone melatonin. During each "night shift" (2300-0700 hours) participants completed performance testing at hourly intervals. In the intervening periods, participants had free time. They were permitted, but not required, to snack every two hours following the testing session of that hour. However, they were not permitted to exercise, shower, sleep, or leave the living quarters during the testing period. Careful monitoring by the researchers ensured wakefulness during the night.

Following the final testing session (at 0700 hours), participants were taken outside for 20 minutes each morning to simulate the natural light exposure a night shiftworker would receive when driving home from a night shift. After this, each participant had breakfast and went to bed at approximately 0800 hours. Again, all participants were
Policy implications

- The current study has implications for the length of breaks between shifts. Rosters need to allow sufficient time off between shifts for both sleep and leisure.

instructed to sleep until they naturally awoke. If they slept beyond 1900 hours, participants were woken by the researcher (this occurred once for two of the participants). On awakening, participants were free to shower and leave the laboratory until 1900 hours. Throughout the study participants were explicitly and repeatedly told that once out of bed, they had to stay awake until the next scheduled sleep period and were not allowed to take naps. Wrist actigraphs were used to confirm this. In addition to abstaining from caffeine and other stimulants for the entire study period, participants were required to avoid bananas, raspberry cordial, and cheese from each night during the collection of saliva samples as a precautionary measure. $^{24}$

\section{Equipment}

Neurobehavioural performance

A 10 minute visual psychomotor vigilance task (PVT) was used to evaluate sustained attention. As the PVT is reported to have a learning curve of $1-3$ trials, ${ }^{25}$ participants were required to individually attend a short training session prior to the experimental period. PVT response time (RT) was selected as the dependent variable in the regression analysis. In accordance with standard methodology, ${ }^{25}$ a reciprocal transformation was applied to the raw data before analysis to correct for proportionality between the mean and SD.

\section{Sleep-wake activity}

Polysomnographic (PSG) data were collected during all of the sleep periods. Sleep-wake state was assessed using a standard EEG montage. Both EEG signals were sampled within a 0.33-70 $\mathrm{Hz}$ bandwidth, digitised at $250 \mathrm{~Hz}$, and filtered with a $50 \mathrm{~Hz}$ notch filter. This was done using the Compumedics 10-20 system (Melbourne, Australia) and Medilog MPA-2 sleep analysis system (Oxford Medical Ltd, UK). The polysomnographic data were double scored according to standard criteria. ${ }^{26}$ The measures derived from the PSG data included total sleep time (TST), sleep onset latency, wake time after sleep onset (WASO), and the amount of SWS, NREM, and REM in each sleep period. Sleep efficiency for each sleep period was calculated as the TST/SPT (sleep period time) $\times 100$.

In addition, participants were required to provide subjective ratings of the quality of each sleep period on a scale of 1 (very good) to 5 (very poor), and rate their alertness levels immediately before and after each sleep period using the Stanford Sleepiness Scale (SSS), a sevenpoint scale where $1=$ "feeling active and vital; alert and wide awake", and 7 = "almost in reverie; sleep onset will be soon; lost struggle to remain awake". To increase recall accuracy, participants were instructed to record the information in their sleep diaries as soon as practicable after waking. For the purpose of analyses, subjective ratings were multiplied by -1 , such that higher scores indicated higher quality or alertness.

\section{Salivary melatonin}

Saliva samples were taken at half hourly intervals from 2000 hours each night until bedtime. Participants chewed the cotton swab of polyester Salivettes (Sarstedt, Numbrecht, Germany) for two minutes, then the saliva samples were stored frozen. Samples were subsequently assayed for the 


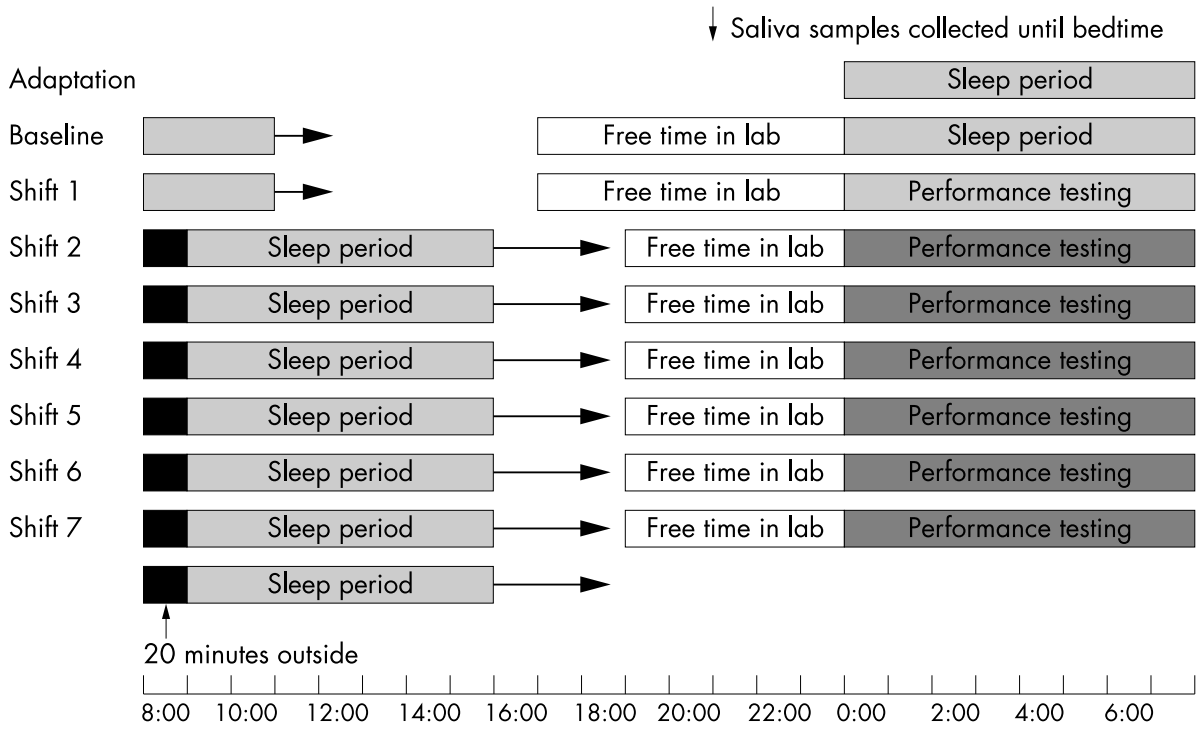

Figure 1 A schematic representation of the simulated night shift protocol.

hormone melatonin by direct radioimmunoassay (described by Voultsios and colleagues $\left.{ }^{24}\right)$.

\section{Circadian phase}

The time of nocturnal salivary melatonin onset (dim light melatonin onset, DLMO) was used as a marker of circadian phase. For each participant the mean (and standard deviation) daytime melatonin concentration was determined using the 2000, 2030, and 2100 hour sample levels from the baseline night and each of the seven night shifts. In accordance with standard methodology, melatonin onset was defined as the time at which salivary melatonin concentration reached a level at least two standard deviations greater than the mean daytime level. ${ }^{24}$ The DLMO for each participant was determined for the baseline night and each of the seven simulated night shifts. The cumulative phase shift (from the baseline night) of each participant was calculated as the difference between the baseline DLMO and the DLMO for the respective night.

\section{Statistical analysis}

To control for interindividual variability in performance, PVT test scores for each subject were expressed relative to a baseline test score obtained at the completion of training. For each night shift, a single score was obtained by calculating the mean of the eight test scores from that shift. Systematic changes in each of the variables (PSG, subjective ratings, cumulative phase shift, and mean relative performance) across the shift week (night shifts 1-7, or day sleeps 1-6) were assessed separately using repeated measures ANOVA. Due to last session effects, data from the sleep period on day 7 were not included in any of the analyses. Missing values due to loss of data ( $8.6 \%$ in total) were replaced by the group mean. For the sleep variables (PSG and subjective ratings) a second ANOVA was also applied. To evaluate the changes in each sleep variable across the week relative to a "typical" night sleep, the nocturnal baseline sleep was included in the analysis with the six daytime sleep periods. For tests that reached significance in this ANOVA, Bonferroni-Dunn post hoc comparisons were performed to determine which day(s) significantly varied from the baseline night. As a repeated measures design was used, the Greenhouse-Geisser procedure was applied to produce more conservative degrees of freedom for all ANOVA analyses. Values are reported as mean (SD).

\section{RESULTS}

\section{Performance}

Figure 2 displays mean relative performance across the seven simulated night shifts. Analysis indicated that there was a significant $\left(\mathrm{F}_{5,70}=6.8, \mathrm{p}=0.0004\right)$ increase in mean performance across the week. Post hoc comparison revealed that mean relative performance on shifts 4-7 significantly differed from performance on the first shift.

\section{Baseline sleep}

Participants averaged 7.52 (SD 0.61) hours sleep (TST) during the baseline night. This was not significantly different $\left(\mathrm{t}_{10}=0.33, \mathrm{p}=0.75\right)$ from the average sleep duration (mean 7.64 hours, SD 0.96) in the week prior to the study (statistics derived from the sleep/wake diaries).

\section{Daytime sleep periods}

\section{Sleep duration}

For the six consecutive daytime sleep periods, subjects obtained 7.02 (SD 1.48), 6.47 (SD 1.30), 7.19 (SD 1.51), 6.99 (SD 1.44), 7.00 (SD 1.20), and 7.24 (SD 1.65) hours of sleep (days 1-6, respectively). On average, each daytime sleep period was reduced by 35 minutes relative to the baseline sleep. TST did not significantly vary across the six daytime sleep periods (table 1). There were also no significant

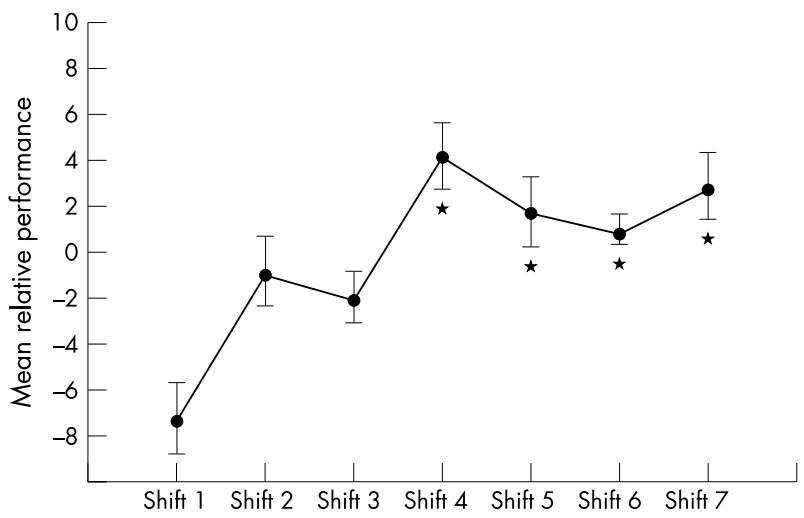

Figure 2 Mean relative performance for the seven simulated night shifts. Values are mean (SEM). *Indicates shifts significantly different from the first shift. 


\begin{tabular}{|c|c|c|c|c|}
\hline & \multicolumn{2}{|c|}{ Shift week } & \multicolumn{2}{|c|}{ Shift week and baseline night } \\
\hline & $F_{5,70}$ & $\mathbf{P}^{*}$ & $F_{6,84}$ & $P^{*}$ \\
\hline \multicolumn{5}{|l|}{ PSG sleep variables } \\
\hline Total sleep time (min) & 1.15 & 0.3371 & 1.67 & 0.1818 \\
\hline Sleep efficiency & 2.23 & 0.0830 & 2.53 & 0.0576 \\
\hline Sleep onset latency & 7.77 & 0.0003 & 12.92 & 0.0001 \\
\hline NREM sleep (min) & 2.51 & 0.0726 & 3.84 & 0.0112 \\
\hline REM sleep (min) & 2.67 & 0.0439 & 2.38 & 0.0538 \\
\hline SWS (min) & 0.49 & 0.6667 & 0.75 & 0.5328 \\
\hline WASO (min) & 3.38 & 0.0271 & 2.62 & 0.0682 \\
\hline \multicolumn{5}{|l|}{ Subjective measures $†$} \\
\hline Sleep quality & 1.71 & 0.1781 & 1.98 & 0.1161 \\
\hline Pre-sleep alertness & 7.94 & 0.0002 & 7.03 & 0.0008 \\
\hline Post-sleep alertness & 3.88 & 0.0127 & 2.51 & 0.0818 \\
\hline Prior wakefulness (min) & 99.62 & $0.0001 \neq$ & 1.23 & $0.3096 \S$ \\
\hline Cumulative sleep debt & 5.10 & $0.0351^{+}$ & & \\
\hline Cumulative phase shift & 67.28 & 0.0001 & 99.46 & 0.0001 \\
\hline \multicolumn{5}{|c|}{$\begin{array}{l}\text { *Corrected by Greenhouse-Geisser epsilon. } \\
\text { † Based on data from } 12 \text { subjects; } D F=5,55 \text { (shift week) or } D F=6,66 \text { (with baseline night). } \\
\text { flncluding the first night shift; } D F=6,84 \text {. } \\
\text { §Excluding the first night shiff; } D F=5,70 \text {. }\end{array}$} \\
\hline
\end{tabular}

differences between TST on the baseline night and any of the subsequent daytime sleeps (fig 3A).

\section{Sleep efficiency}

As can be seen in fig 3B, sleep efficiency showed an obvious trend towards greater efficiency across the consecutive daytime sleeps (from 92.1 (1.9) to 94.2 (2.0)\%). However, the pattern was not statistically reliable $\left(\mathrm{F}_{5,70}=2.23\right.$, $\mathrm{p}=0.058)$, nor did any of the daytime sleeps significantly differ from the baseline night (90.9 (5.5)\%).

\section{Sleep onset latency}

Sleep onset latency (SOL) significantly increased $\left(\mathrm{F}_{5,70}=7.8, \mathrm{p}=0.0003\right)$ across the daytime sleep periods (from 4.0 (3.0) to 11.0 (5.6) minutes). Post hoc comparison revealed that for all six of the daytime sleeps, SOL was significantly $(\mathrm{p}=0.0001-0.0013)$ shorter than on the baseline night (16.8 (10.5) minutes) (fig 3C).

\section{Sleep stage physiology}

No significant differences were found in the amount of NREM or SWS sleep across the week. However, the amount of NREM sleep obtained during the second daytime sleep was significantly ( $p=0.0001$ ) less than baseline (fig 4B). As shown in fig 4C, the amount of REM sleep obtained during the day sleeps significantly increased $\left(\mathrm{F}_{5,70}=2.7\right.$, $\mathrm{p}=0.0439$ ) across the week (from 97.9 (31.6) to 113.6 (27.3) minutes). However, the total REM in each of the daytime sleeps did not significantly differ from the baseline night (120.0 (27.2) minutes). Conversely, there was a significant decrease $\left(\mathrm{F}_{5,70}=3.4, \mathrm{p}=0.0271\right)$ in wake time after sleep onset (WASO) across the week (from 26.0 (10.0) to 14.9 (10.1) minutes). As can be seen in fig $4 \mathrm{D}$, WASO during each of the six daytime sleeps did not significantly differ from the baseline night (29.6 (26.7) minutes).

\section{Subjective sleep measures}

Subjective sleep quality did not significantly vary across the six daytime sleep periods (fig 5A). There were also no significant differences between subjective sleep quality on the baseline night and any of the subsequent daytime sleeps. In contrast, subjective alertness significantly increased across the week, for both pre-sleep $\left(\mathrm{F}_{5,55}=7.9, \mathrm{p}=0.0002\right)$ and post-sleep $\left(\mathrm{F}_{5,55}=3.9, \mathrm{p}=0.0127\right)$ ratings. Post hoc comparisons revealed that ratings of pre-sleep alertness were poorer for day sleeps $1-3 \quad(p=0.0001-0.0002)$ when compared to the baseline night (fig 5B). However, no ratings made following the daytime sleep periods significantly differed from those made following the baseline night (fig 5C).

\section{Hours of prior wakefulness}

When analyses included the first shift, hours of prior wakefulness significantly varied $\left(\mathrm{F}_{5,70}=99.6, \mathrm{p}=0.0001\right)$ across the week. Post hoc comparisons (fig 6B) revealed that the effect $(p=0.0001)$ was between the first shift (13.7 (0.8) hours) and each of the subsequent six shifts (range 6.8 (1.7) to 7.5 (1.4) hours). When prior wake for the first shift was excluded, no significant differences were found.

\section{Cumulative sleep debt}

The difference between TST on the baseline night and TST for each daytime sleep period was calculated for each individual to determine the sleep debt (or gain) associated with each daytime period. The cumulative sleep debt was calculated by adding the "sleep debt" associated with (1) that day sleep and, (2) each preceding day sleep. As seen in fig 6A, the cumulative sleep debt significantly increased $\left(\mathrm{F}_{5,70}=5.1\right.$, $p=0.0351)$ across the week. Prior to the final night shift, the average sleep debt was 3.53 (SD 5.62) hours.

\section{Cumulative phase shift}

The melatonin profile also significantly shifted $\left(\mathrm{F}_{5,70}=67.3\right.$, $\mathrm{p}=0.0001$ ) across the week (fig 6C). A mean phase delay of 5.5 (1.63) hours was observed after six consecutive nights.

\section{DISCUSSION}

In general, seven consecutive nights of simulated shift work did not have a negative effect on the quantity and quality of sleep obtained in the current laboratory study. Rather, sleep appeared to improve as the week progressed. In line with previous findings, sleep onset latency (fig 3C) for each of the day sleeps was significantly shorter than the nocturnal baseline sleep..$^{28}$ In addition, there was a significant decrease in wake time across the week (fig 4D), and subsequently a trend towards increasing sleep efficiencies as the week progressed (fig 3B). 

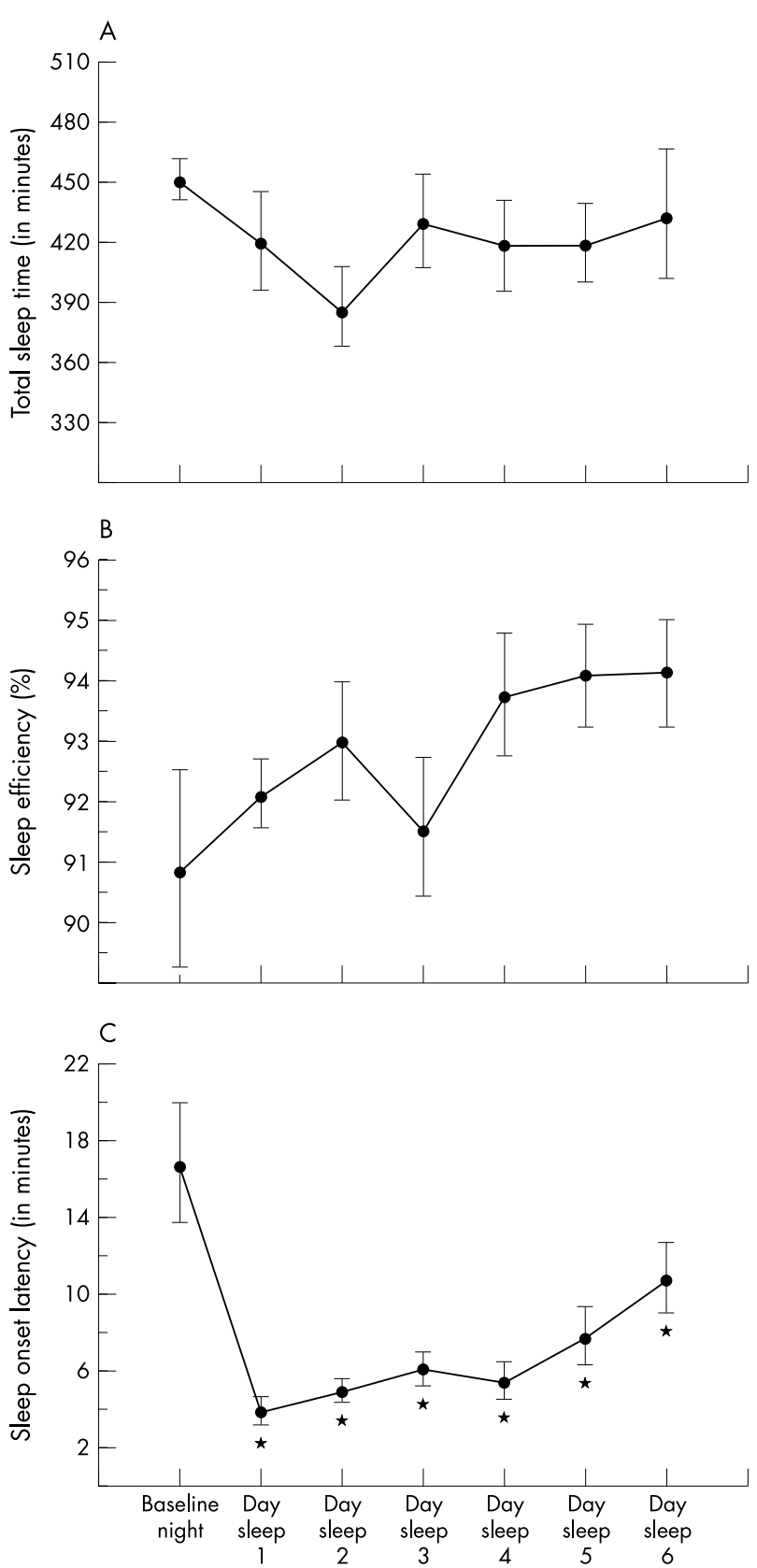

Figure 3 Mean sleep duration (A), sleep efficiency (B), and sleep onset latency (C) for the nocturnal baseline sleep period and each of the day time sleep periods. Values are mean (SEM). "Indicates days significantly different from baseline night.

The general consensus that has emerged from previous questionnaire ${ }^{29-33}$ and $E \mathrm{EG}^{34-39}$ studies of sleep in shiftworkers is that shift work negatively impacts on both sleep duration and sleep quality. Specifically, studies have recorded a 2-4 hour reduction in the duration of daytime sleep, and poorer sleep quality due to more time spent awake. However, the shortened daytime sleep (of reduced quality) characteristic of shiftworkers was not observed in this study. Rather, the daytime sleep periods observed in the current study were not only of equivalent duration to the sleep obtained during the nocturnal baseline, but longer than reported in previous studies of shift workers ${ }^{12}{ }^{40}$ (fig 3A).

The comparatively good daytime sleep observed in the current study is probably due to the fact that the subjects participating were considerably younger (and probably healthier) than most shiftworkers. Research has shown that age is a significant predictor of sleep length and quality. ${ }^{31-33} 41$ In general, tolerance for shiftwork and sleep decreases with increasing age such that sleep in older workers is shorter, lighter, and more fragmented. ${ }^{42}{ }^{43}$ The environmental conditions associated with the study probably had a substantial impact on the day sleep also. While not the only contributing factor, environmental disturbances such as noise and light are frequently considered a reason for difficulties encountered when attempting to sleep during the day. ${ }^{44}{ }^{45}$ In the current study the participants were provided with very dark and quiet sleeping areas that would have facilitated sound, unbroken sleep. It is worth noting however, that shortened daytime sleep has previously been reported under similarly optimal laboratory conditions. ${ }^{11}$

A third factor that probably contributed substantially to the good daytime sleep was the reduction or absence of competing social factors. Social and domestic factors often greatly influence how much sleep shiftworkers obtain. ${ }^{46}$ It is clear from studies comparing eight versus twelve hour shifts that night workers regard increased time for social and domestic activities as a major priority. ${ }^{47} 48$ Thus, sleep may often be curtailed to spend time with friends, family, or to complete domestic activities. For example, the investigation by Parkes ${ }^{41}$ of onshore and offshore oil workers showed that the daytime sleep of offshore workers was longer, partly due to less psychosocial factors. In addition, if a shiftworker has children that need to be cared for, their sleep will probably be shorter than that of colleagues without children. ${ }^{49}$ Moreover, family life may cause a reduction in sleep not necessarily through choice, but because children often have less regard for the sleep needs of parents during the day.

Participants in the current study were encouraged to sleep for as long as they could, so that they could more easily maintain wakefulness and work at night. While participants were allowed to leave the laboratory once they had terminated their daytime sleep period, many chose to stay. Indeed, many turned the laboratory into their home for the week, having friends visit them and only leaving for brief periods to get some exercise. Unlike most shiftworkers, none of the participants in the current study had children, nor did many of them have any social or family commitments that needed to be attended to during the study. As such, with minimal competing social factors, sleep was their major, and sometimes only, priority. This suggests that with reduced psychosocial input, sleep during the day may be as long and as efficient as nocturnal sleep during consecutive night shifts.

Subjective ratings suggest that the recuperative value of the day sleep improved across the week. As the week progressed, ratings of alertness made on awakening from the respective daytime sleep period increased (fig 5C). Interestingly, for most if not all of the daytime sleep periods, objective and subjective data suggested that sleep during the day was better than the nocturnal sleep. In light of these findings, it was considered possible that the nocturnal baseline sleep was not representative of the participants' normal sleep length. For example, if participants in this study had not fully adjusted to the laboratory, their nocturnal baseline sleep may have been poorer than usual. Alternatively, research indicates that the night sleep before the first night shift is typically longer than usual to decrease prior wakefulness,$^{27}{ }^{50}$ thus the baseline sleep duration may have been greater than usual. However, analyses of sleep diaries obtained during the week prior to the study suggest that the nocturnal baseline sleep observed in the current study was very similar in length to the average sleep duration obtained during the week prior to the study, and thus considered fairly representative. 

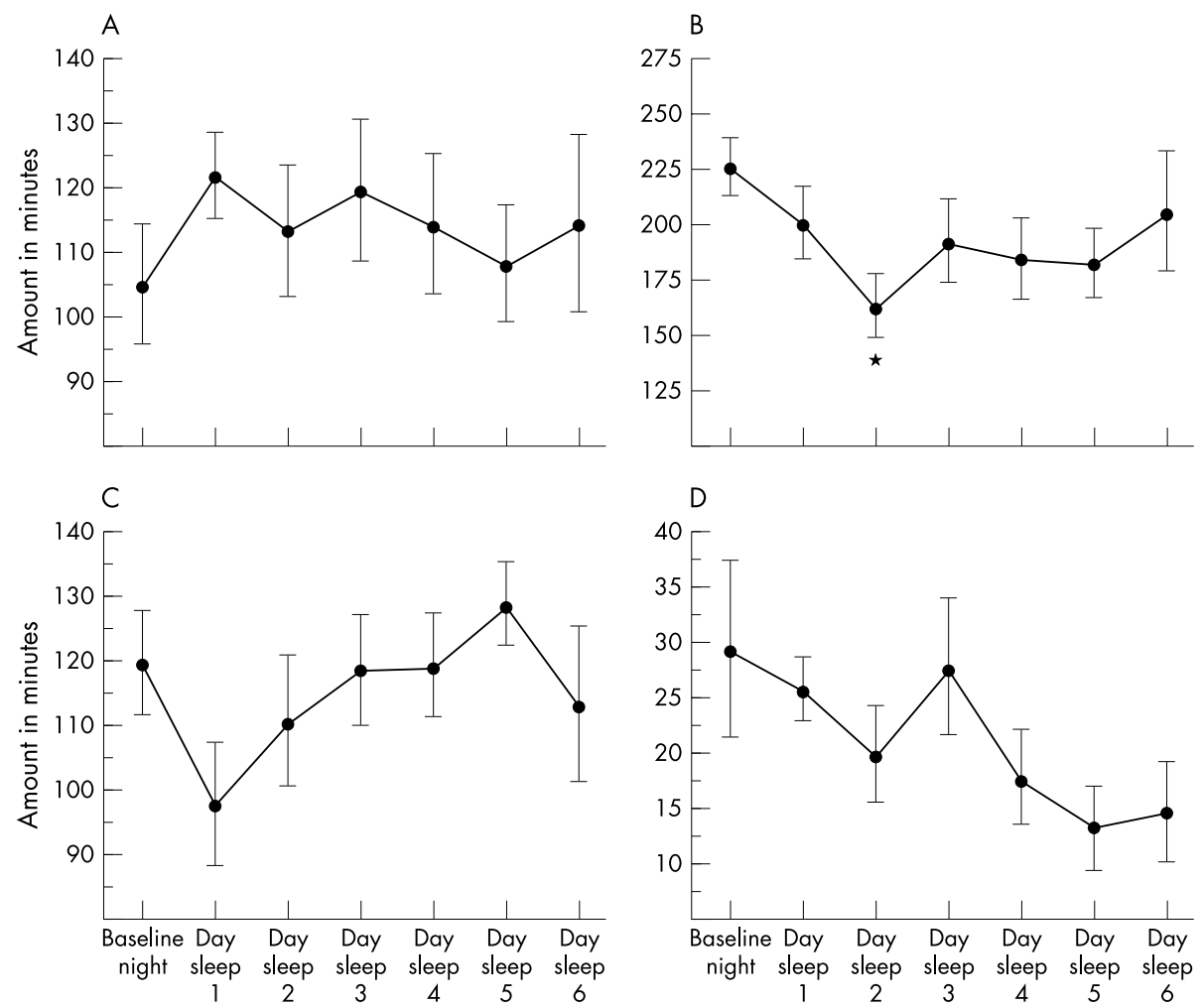

Figure 4 Amount of slow wave sleep (A), NREM sleep (B), REM sleep (C), and wake time after sleep onset (D) during the nocturnal baseline sleep period and each of the daytime sleep periods. Values are mean (SEM). *Indicates days significantly different from the baseline night.

Several possible reasons may account for the improvement in sleep quality across the week. Despite good daytime sleep, a small cumulative sleep debt developed (fig 6A). Prior to the final night shift the average cumulative sleep debt was approximately four hours. While this sleep debt is substantially smaller than that reported in previous studies, ${ }^{12}$ it is possible that with the increasing sleep debt participants were becoming increasingly tired, and thus sleeping better on each consecutive day. However, subjective ratings of alertness prior to each sleep period are not in line with this suggestion. Rather, participants felt that prior to each sleep period they were less tired as the study progressed (fig 5B). An alternative reason may be that despite the inclusion of an adaptation night in the current study, participants had not completely adjusted to the "strangeness" of the laboratory environment. If this were the case, it could be assumed that as the week progressed they became increasingly more used to their environment, which resulted in a subsequent improvement in their sleep. In addition to potential effects of "laboratory adaptation", the trend towards more efficient sleep as the week progressed was probably related to circadian adaptation. That is, sleep improved as individuals became more biologically adapted to sleeping during the day and working at night.

In line with this suggestion, the findings indicate that partial circadian adaptation to the new sleep-wake schedule occurred. According to the data, a mean phase delay of 5.5 hours was observed after six consecutive nights, indicating an average phase delay of 0.79 hours per day (fig 6C). Phase delays of similar magnitude have been reported in several other laboratory studies of simulated shiftwork with non-natural sunlight exposure. In previous studies, the rate at which circadian adjustment to night work occurred ranged from 0.2 hours to 1.4 hours per day. ${ }^{51-53}$ Moreover, it is worth noting that ordinary dim light was sufficient for phase shifting the circadian system in the current study. Recent studies have similarly reported this observation. ${ }^{54}$

Previous research has found that a phase shift of lower magnitude, or none at all, is observed in field studies involving more outdoor activity and thus exposure to morning light. ${ }^{19}$ This difference in circadian adaptation depending on light exposure has also been reproduced within the laboratory. For example, in a series of simulated shift work studies, Eastman and colleagues ${ }^{55}$ showed that wearing dark goggles to reduce the intensity of phase advancing sunlight while travelling home after a night shift can promote circadian phase delays. Interestingly, in the current study participants sat outside exposed to morning light (with no dark glasses) for 20 minutes each morning, prior to going to bed. In addition, they were allowed to leave the laboratory in the afternoons, thus exposing themselves to natural light. It is highly unlikely that the light exposure during the afternoon significantly affected phase shifting, because it occurred during the "dead zone" of the phase response curve. ${ }^{56-58}$ In contrast, the former had the potential to reduce or eliminate potential phase delays to phase advance. Yet in the current study the morning exposure appeared to have little if no effect on phase shifting, potentially due to the briefness of the period (20 minutes).

It is also worth noting that the total absence of light in the participants' room during their sleep period probably facilitated the phase delay. Thus, it is possible that in real shiftworkers who would typically be exposed to more light in the morning (due to the drive home and bedroom windows), the phase shift would not be as large as that reported in this study. As a final point, it is interesting to note that a small phase delay was observed prior to the first night shift, despite the fact that nothing "unusual" had occurred at the stage. While this is not an uncommon finding in laboratory studies, ${ }^{58}$ such a delay may not occur in the real world. 

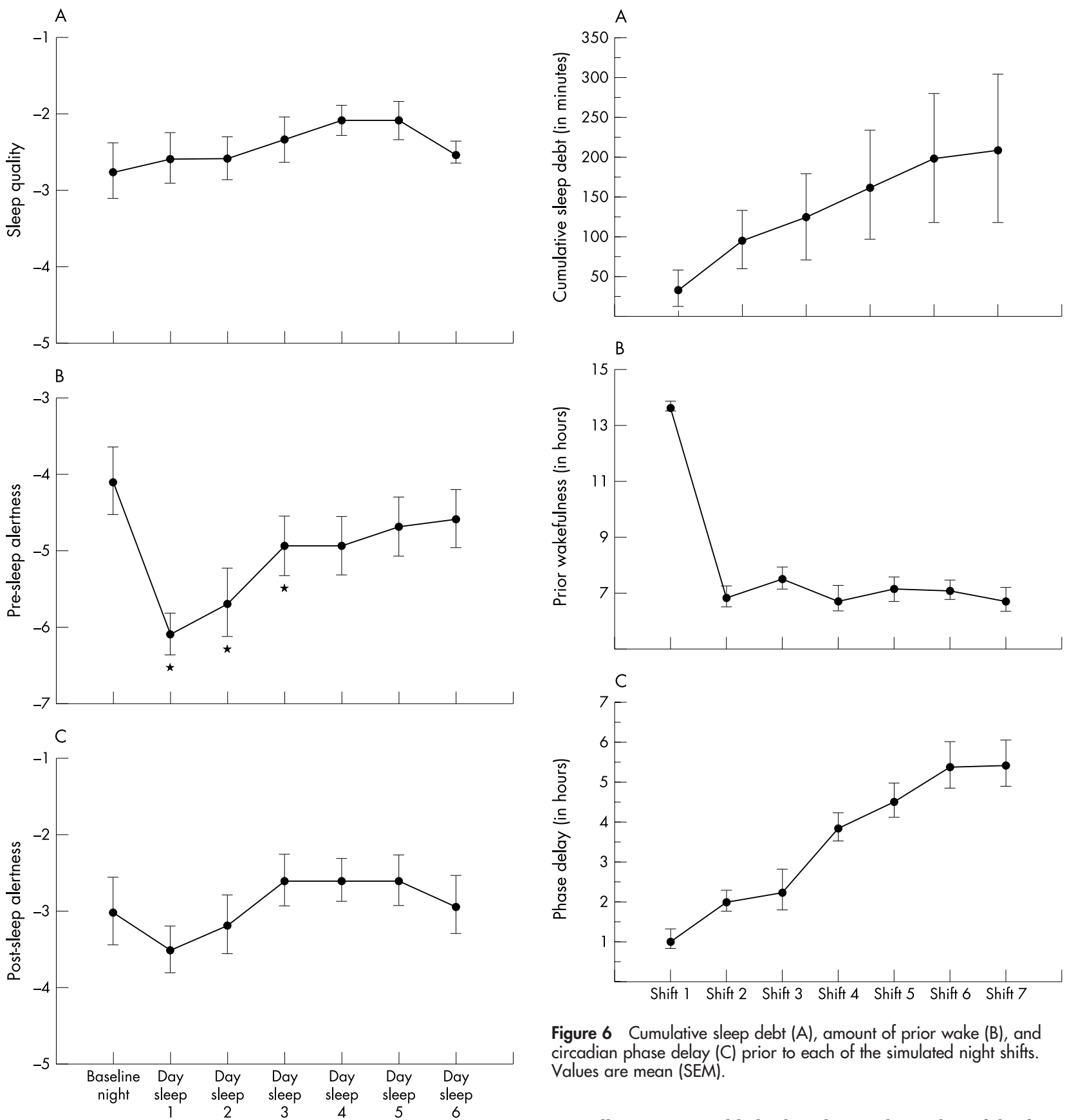

Figure 6 Cumulative sleep debt (A), amount of prior wake (B), and circadian phase delay (C) prior to each of the simulated night shifts. Values are mean (SEM).

Figure 5 Sleep diary ratings of sleep quality (A), and alertness prior to (B) and on awakening from (C) the nocturnal baseline and daytime sleep periods. Values are mean (SEM). *Indicates days significantly different from baseline night.

While it was initially expected that response time performance would deteriorate over the course of the simulated shift week as sleep loss accumulated, ${ }^{12}$ this was not the case. Rather, in the current study performance improved across the week of simulated night shifts (fig 2). Specifically, performance was significantly less impaired on nights 4-7 compared to the first night when the performance decrements were greatest. A reason for this may be that the cumulative sleep debt was substantially smaller than has been previously reported, due to the particularly good daytime sleep participants had. Thus, contrary to the findings of the current study, in real night workers where day sleep is

typically worse, it is likely that the resulting sleep debt does exacerbate other causes of night-time performance deficits.

It is likely that the improvement in performance across the week was also, in large part, due to circadian adaptation. That is, as individuals progressively adapted to working consecutive nights (as indicated by the phase delay), a concomitant increase in performance was observed. This finding was intuitively expected. While few studies have systematically investigated the relation between performance and circadian phase in shiftwork, previous research indicates that other detrimental symptoms of night work, such as poor sleep and fatigue, are reduced in individuals that exhibit phase shifts. ${ }^{54}$

Particularly for the first shift, it is probable that prior wakefulness also influenced performance during the nights shifts. Extended time of wakefulness prior to the night shift is consistently recognised as a problem for shiftworkers. Research indicates that there is usually very little sleep prior to the first night shift in a sequence. ${ }^{70}$ Thus, whereas the 
amount of wakefulness prior to a day shift is usually only l2 hours, the amount of time spent awake prior to the beginning of a night shift is usually extended to 10-16 hours. Furthermore, by the end of a night shift prior wakefulness is extended to over 20 hours. ${ }^{27}$ This was the case in the current study. As can be seen in fig $6 \mathrm{~B}$, participants were awake for nearly 14 hours prior to commencing the first simulated night shift and thus for over 20 hours prior to the final testing session (0600 hours). Thus, it is not surprising that significant performance decrements were observed during the first shift.

Taken together, the findings of the current study have certain implication for night workers, particularly those who work several consecutive night shifts. Firstly, they emphasise the importance of obtaining sufficient sleep during the day. When daytime sleep is of adequate quantity and quality, it is apparent that the sleep debt that accumulates during consecutive night shifts is relatively small and thus does not exacerbate decrements in night-time performance. It is possible that educating night workers about the impact of competing psychosocial factors (that is, family and friends) and environmental factors (that is, noise and light) on sleep may minimise sleep loss. In addition, night workers should be encouraged to adopt behaviours that will facilitate circadian adaptation, such as wearing dark glasses to shield themselves from morning light after the night shift. It is duly noted however, that it is often difficult to eliminate noise and light in one's sleeping environment. Furthermore, it is highly unlikely that shiftworkers will willingly isolate themselves and totally forgo family and social commitments for the sake of obtaining sufficient sleep. Thus, in practice, night workers are less likely to adapt to night work than did the participants in the current study.

\section{ACKNOWLEDGEMENTS}

We gratefully acknowledge the service provided by Compumedics, Pty Ltd. This research was funded by a large Australian Research Council grant.

\section{Authors' affiliations}

N Lamond, J Dorrian, G D Roach, K McCulloch, A L Holmes, H J Burgess, A Fletcher, D Dawson, The Centre for Sleep Research, The Queen Elizabeth Hospital, South Australia

\section{REFERENCES}

1 Folkard S, Monk T. Shiftwork and performance. Hum Factors 1979:21:483-92.

2 Akerstedt T. Sleepiness as a consequence of shiftwork. Sleep 1988;1 1:17-34.

3 Mitler M, Carskadon AM, Czeisler CA, et al. Catastrophes, sleep and public policy: Concensus report. Sleep 1988;11:100-9.

4 Folkard S. Diurnal variation in logical reasoning. Br J Psychol 1975;66:1-8.

5 Czeisler C, Weitzman E, Moore-Ede M, et al. Human sleep: its duration and organisation depend on its circadian phase. Science 1980;210:1264-7.

6 Dijk DJ, Duffy JF, Czeisler CA. Circadian and sleep/wake dependent aspects of subjective alertness and cognitive performance. J Sleep Res 1992;1:112-17.

7 Mills JN, Minors DS, Waterhouse JM. The circadian rhythms of human subjects without timepieces or indication of the alternation of day and night. J Physiol 1974:240:567-94.

8 Carskadon MA, Dement WC. Sleep studies on a 90-minute day. Electroencephalogy and Neurophysiology 1975;39:145-55.

9 Carskadon MA, Dement WC. Sleepiness and sleep state on a 90-min schedule. Psychophysiology 1977;14:127-33.

10 Strogatz SH. The mathematical structure of the human sleep-wake cycle. Berlin: Springer-Verlag, 1986.

11 Akerstedt T, Gillberg $M$. The circadian variation of experimentally displaced sleep. Sleep 1981:4:159-69.

12 Tilley AJ, Wilkinson RT, Warren PSG, et al. The sleep and performance of shiftworkers. Hum Factors 1982;24:629-41.

13 Rutenfranz J, Colquhoun W, Knauth $\mathrm{P}$, et al. Biomedical and psychological aspects of shift work. Scand J Work Environ Health 1977:3:165-82

14 Colquhoun WP, Blake MJF, Edwards RS. Experimental studies of shift-work II: stabilized 8-hour shift systems. Ergonomics 1968;12:865-82.

15 Aschoff J, Hoffman $\mathrm{K}$, Pohl H, et al. Reentrainment of circadian rhythms after phase-shifts of the zeitgeiber. Chronobiologia 1975;2:23.
16 Minors DS, Waterhouse JM. Circadian rhythms and the human. Bristol: Wright PSG, 1981

17 Moore-Ede M, Sulzman F. Fuller C. The clocks that time us. Cambridge: Harvard University Press, 1982.

18 Sack RL, Blood ML, Lewy AJ. Melatonin rhythms in night shift workers. Sleep 1992;15:434-41.

19 Harma M. Circadian adaptation to shift work. A review. In: Hornberger S, Knauth P, eds. Shiftwork in the 21 st century. Germany: Peter Lang, 2000:125-30.

20 Folkard S, Monk TH, Lobban MC. Short and long term adjustment of circadian rhythms in "permanent" night nurses. Ergonomics 1978;21:785-99.

21 Minors DS, Waterhouse JM. Separating the endogenous and exogenous components of the circadian rhythm of body temperature during night work using some "purification" models. Ergonomics 1993:36:497-507.

22 Wever RA. The circadian system of man. New York: Springer, 1979.

23 Lamond N, Dorrian J, Holmes AL, et al. Equating the effects of acute and cumulative partial sleep deprivation on performance. Sleep 2000;23/supp 2):A73.

24 Voultsios A, Kennaway DJ, Dawson D. Salivary melatonin as a circadian phase marker: validation and comparison to plasma melatonin. J Biol Rhythms 1997; 12:457-66.

25 Dinges D, Pack F, Williams K, et al. Cumulative sleepiness, mood disturbance, and psychomotor vigilance performance decrements during a week of sleep restricted to 4-5 hours per night. Sleep 1997;20:267-7.

26 Rechtschaffen A, Kales A. A manual of standardized terminology, techniques and scoring system for sleep stages of human subjects. Los Angeles: Brain Information Service/Brain Research Institute, 1968.

27 Tabachnik BG, Fidell LS. Using multivariate statistics, 4th edition. Allyn and Bacon: Boston, 2000

28 Akerstedt T. Is there an optimal sleep-wake pattern in shift work? Scand J Work Environ Health 1998;24(suppl 3): 18-27.

29 Tune GS. Sleep and wakefulness in a group of shiftworkers. $\mathrm{Br} J$ Ind Med 1969;8:54-8.

30 Foret J, Lantin G. The sleep of train drivers: an example of the effects of irregular work schedules on sleep. In: Colquhoun WP, ed. Aspects of human efficiency. Diurnal rhythm and loss of sleep. London: The English Universities Press Ltd, 1972.

31 Foret J, Bensimon G, Benoit $O$, et al. Quality of sleep as a function of age and shift work. In: Reinberg A, Vieux N, Andlauer P, eds. Night and shift work: biological and social aspects. Oxford: Pergamon Press, 1981.

32 Akerstedt T, Gillberg M. Sleep disturbances and shift work. In: Reinberg A, Vieux N, Andlauer P, eds. Night and shift work: biological and social aspects. Oxford: Pergamon Press, 1981.

33 Akerstedt T, Torsvall L. Shift-dependent well-being and individual differences. Ergonomics 1981:24:265-73.

34 Kripke DF, Cook B, Lewis OF. Sleep of night workers: EEG recordings. Psychophysiology 1971;7:377-84.

35 Bryden G, Holdstock TL. Effects of night duty on sleep patterns of nurses. Psychophysiology 1973;10:36-42.

36 Tepas DI, Walsh JK, Moss PD, et al. Polysomnographic correlates of shift worker performance in the laboratory. In: Reinberg A, Vieux N, Andlaver P, eds. Night and shift work: biological and social aspects. London: Pergamon Press, 1981

37 Tilley AJ, Wilkinson RT, Drud M. Night and day shifts compared in terms of the quality and quantity of sleep recorded in the home and performance measured at work: a pilot study. In: Reinberg A, Vieux N, Andlauer P, eds. Night and shift work: biological and social aspects. Oxford: Pergamon Press, 1981.

38 Torsvall L, Akerstedt T, Gillander K, et al. Sleep on the night shift: 24-hour EEG monitoring of spontaneous sleep/wake behaviour. Psychophysiology $1989 ; 26: 352-8$

39 Akerstdet T, Arnetz BB, Anderzen I. Physicians during and following night call duty-36hour ambulatory recording of sleep. Electroencephalogr Clin Neurophysiol 1990;76:193-6.

40 Wilkinson RT. How fast should the night shift rotate? Ergonomics 1992;35: 1425-46.

41 Parkes K. Sleep patterns, shiftwork, and individual differences: a comparison of onshore and offshore control-room operators. Ergonomics 1994:37:827-44.

42 Costa G, Lievore F, Casaletti G, et al. Circadian characteristics influencing interindividual differences in tolerance and adjustment to shiftwork. Ergonomics 1989;32:373-85.

43 Tepas D, Duchon J, Gersten A. Shiftwork and the older worker. Exp Aging Res 1993; 19:295-320

44 Thiis-Evensen E. Shift work and health. Ind Med Surg 1958;27:439-97.

45 Knauth P, Rutenfranz J. The effects of noise on the sleep of night-workers. In: Colquhoun P, Folkard S, Knauth P, Rutenfranz J, eds. Experimental studies of shift work. Pladen: Westdeutscher Verlag, 1975:57-65.

46 Monk TH, Wagner JA. Social factors can outweigh biological ones in determining night shift safety. Hum Factors 1989;31:721-4.

47 Lowden A, Kecklund G, Axelsson J, et al. Change from 8-hour shift to a 12 hour shift, attitudes, sleep, sleepiness and performance. Scand J Work Environ Health 1998;24(suppl 3):69-75.

48 Smith PA, Wright BM, Mackey RW, et al. Change from slowly rotating 8-hour shifts to rapidly rotating 8 -hour and 12-hour shifts using participative shift roster design. Scand J Work Environ Health 1998;24(suppl 3):55-61.

49 Knauth P. Speed and direction of shift rotation. J Sleep Res 1995;4(suppl 2):41-6.

50 Gillberg M. Subjective alertness and sleep quality in connection with permanent 12-hour day and night shifts. Scand J Work Environ Health 1998;24(suppl 3):76-81. 
51 Dawson D Campbell SS. Timed exposure to bright light improves sleep and alertness during simulated night shitts. Sleep 1991;14:511-16.

52 Dawson D, Encel N, Lushington K. Improving adaptation to simulated night shift: Timed exposure to bright light versus daytime melatonin administration. Sleep 1995; 18:11-21.

53 Harma M, Waterhouse J, Minors D, et al. Effect of masking on circadian adjustment and interindividual differences on a rapidly rotating shift schedule. Scand J Work Environ Health 1994;20:55-61.

54 Martin SK, Eastman Cl. Medium-intensity light produces circadian rhythm adaptation to simulated night-shift work. Sleep 1998;21:154-65.

55 Eastman CI, Stewart KT, Mahoney MP, et al. Dark goggles and bright light improve circadian rhythm adaptation to night-shift work. Sleep 1994; 17:535-43.

56 Kronaver RE. Circadian rhythms. In: Cooper R, ed. Sleep. London: Chapman and Hall Medical, 1994:96-134.

57 Kryger MH, Roth T, Carskadon M. Circadian rhythms in humans: an overview. In: Kryger MH, Roth T, Dement WC, eds. Principles and practice of sleep medicine. Philadelphia: WB Saunders Company, 1994:301-8.

58 Czeisler CA, Wright KP. Influence of light on circadian rhythmicity in humans. In: Turek FW, Zee PC, eds. Regulation of sleep and circadian rhythms. New York: Marcel Dekker Inc., 1999

59 Czeisler CA, Duffy JF, Shanahan TL, et al. Stability, precision, and near-24-hour period of the human circadian pacemaker. Science 1999:284:2177-81.
60 Gillberg M, Kecklund G, Akerstedt T. Relations between performance and subjective ratings of sleepiness during a night awake. Sleep 1994; 17:236-41

61 Glovinsky PB, Spielman AJ, Carroll P, et al. Sleepiness and REM sleep recurrence: the effects of stage 2 and REM sleep awakenings. Psychophysiology 1990;27:552-9

62 Devoto A, Lucidi F, Violani C, et al. Effects of different sleep reductions on daytime sleepiness. Sleep 1999;22:336-43.

63 Bonnet MH. The effect of sleep disruption on sleep, performance and mood. Sleep 1985:8:11-19.

64 Bonnet M. Performance and sleepiness as a function of frequency and placement of sleep disruption. Psychophysiology 1986;23:263-71.

65 Bonnet MH. Sleep restoration as a function of periodic awakening, movement, or electroencephalographic change. Sleep 1987;10:364-73.

66 Bonnet MH. Infrequent periodic sleep disruption: effects on sleep, performance and mood. Physiol Behav 1989;45:1049-55.

67 Levine B, Roehrs T, Stepanski E, et al. Fragmenting sleep diminishes its recuperative value. Sleep 1987;10:590-9.

68 Stepanski E, Lamphere J, Badia $\mathrm{P}$, et al. Sleep fragmentation and daytime sleepiness. Sleep 1984;7:18-26.

69 Stepanski E, Lamphere J, Roehrs T, et al. Experimental sleep fragmentation in normal subjects. Int J Neurosci 1987;33:207-14.

70 Knauth P, Landau K, Droge $C$, et al. Duration of sleep depending on the type of shift work. Int Arch Occup Environ Health 1980;46:167-77. 